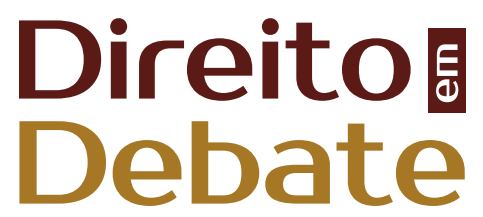

Revista do Departamento de Ciências Jurídicas e Sociais da Unijuí Editora Unijuí - Ano XXIX - n. 53 - jul./dez. 2020 - ISSN 2176-6622

\title{
EXTRATIVISMO E A DIVISÃO INTERNACIONAL DO (DIREITO DO) TRABALHO: Uma Abordagem Ecossocialista
}

\author{
http://dx.doi.org/10.21527/2176-6622.2020.54.106-117
}

Recebido em: 20/4/2020

Aceito em: 6/9/2020

Gustavo Seferian

Professor-adjunto da Faculdade de Direito da Universidade Federal de Minas Gerais. Membro do corpo permanente do Programa de Pós-Graduação em Direito da Universidade Federal de Minas Gerais. Doutor (2017), mestre (2012) e bacharel (2008) em Direito pela Universidade de São Paulo. Pesquisador convidado, em sede pós-doutoral, do CéSor/EHESS/CNRS (2018). Pesquisador-líder do Grupo de Pesquisa Trabalho e Capital (GPTC-USP) e coordenador do Núcleo de Estudos Interpretar e Transformar o Brasil (leTB-UFMG). Membro do Instituto de Pesquisa Direitos e Movimentos Sociais (IPDMS). http://lattes.cnpq.br/6051232864493698. http://orcid. org/0000-0002-5587-6734. seferianacad@gmail.com

\section{RESUMO}

$\mathrm{O}$ artigo trata das articulações entre a divisão internacional do trabalho e o desenvolvimento histórico do Direito do Trabalho. Ampara-se no materialismo histórico e dialético e no revolvimento bibliográfico para firmar seu desenvolvimento, que, se pautando em experiências do trabalho extrativo, sobretudo minerário, e nas perspectivas do ecossocialismo, evidencia o papel combinado da exploração da força de trabalho e do meio ambiente, bem como os limites estruturais do Direito do Trabalho nas realidades dependentes e periféricas.

Palavras-chave: Divisão internacional do direito do trabalho. Ecossocialismo. Extrativismo.

EXTRATIVISMO Y LA DIVISIÓN INTERNACIONAL (DEL DERECHO) LABORAL: UN ENFOQUE ECOSOCIALISTA

\section{RESUMEN}

El artículo aborda las articulaciones entre la división internacional del trabajo y el desarrollo histórico del derecho laboral. Está respaldado por el materialismo histórico y dialéctico y la consulta bibliográfica para establecer su desarrollo, que se basa en experiencias de trabajo extractivo, especialmente en la minería, y en las perspectivas ecosocialistas destaca el papel combinado de la explotación de la fuerza laboral y el medio ambiente, así como los límites estructurales del derecho laboral en realidades dependientes y periféricas.

Palavras clave: División internacional del derecho del trabajo. Ecosocialismo. Extractivismo.

\section{SUMÁRIO}

1 Introdução. 2 Uma discussão histórica, inerente à humanidade e que se particulariza no capitalismo. 3 Singularidade periférica brasileira e a mineração. 4 Regulamentação da exploração e luta de classe entre centro e periferia: elementos para compreensão de uma divisão internacional do Direito do Trabalho. 50 trabalho na mineração ontem e hoje na constituição da regulamentação da contratação da força de trabalho no Brasil. 6 Conclusão. 7 Referências. 


\section{INTRODUÇÃO}

Propomos, com este artigo, tratar das dinâmicas econômicas do extrativismo, seu engendramento com a Divisão Internacional do Trabalho (DIT) e o modo como este complexo de fatores determina as diferentes formações do Direito do Trabalho mundo afora. Esta abordagem possibilitará pensar uma divisão internacional do Direito do Trabalho que proporciona diversos desenhos nacionalizados da regulamentação das relações de trabalho, que se colocam estruturalmente funcionais aos processos de acumulação de capitais desenvolvidos nas variadas realidades sociais da civilização capitalista, moderna e industrial.

De ancestralidade e atualidade comuns, de interesse regional e internacional, de impactos particulares e de totalidade, com nuances subjetivas e estruturais, o tema é inerente e indissociavelmente ligado ao desenvolvimento do modo capitalista de produção, e no seu cerne deve ser considerado. Em outras palavras, é um tema que comporta temporalidades e espacialidades diversas para sua abordagem. Definimos por recorte, porém, a sua lida contemporânea, pautando-nos na apreensão do extrativismo e dos contornos da divisão internacional do (direito do) trabalho desde o referencial latino-americano, com fundamental preocupação com a realidade brasileira.

Abordando a problemática desde uma perspectiva multidisciplinar, pautando-nos no método materialismo dialético e histórico, operando as categorias fundamentais da Crítica da Economia Política e preocupados com a estratégia revolucionária ecossocialista (LÖWY, 2010), buscamos uma leitura crítica do Direito do Trabalho, tomando a perspectiva de seu uso tático (SEFERIAN, 2017), sempre reconhecidos os limites estruturais da juridicidade (SARTORI, 2016) e sua possibilidade de tensão política.

Desse modo, a exposição sustentará (i) que o extrativismo é inerente às dinâmicas de trabalho, haja vista que a interação humana com a natureza, no seu processo de produção de valores de uso, reclama, em alguma medida e desde priscas eras, a realização de atividades extrativas; (ii) que tais atividades extrativas assumem nova qualidade e funcionalização ante o imperativo do valor de troca sobre o valor de uso dado com a afirmação da relação social do capital e do modo de produção capitalista, de início no contexto da Europa Ocidental e, posteriormente - na cadência de seu desenvolvimento desigual e combinado -, na quase integralidade do globo; (iii) que a afirmação capitalista, desde o curso do século 20, arranja as dinâmicas de extração e produção de forma diferenciada, marcada por elementos geopolíticos, que, na obra marxiana e na tradição marxista, passaram a ser tratadas desde a chave da DIT; (iv) que esta DIT engendra diversas formas de exploração da força de trabalho - sejam formas sociais pré-capitalistas, seja o assalariamento -, definindo, de modo articulado com o processo de luta de classes e em específicas e distintas cadências, a regulamentação jurídica da contratação da força de trabalho, a denotar uma divisão internacional do Direito do Trabalho; tudo para sinalizar $(v)$ que os processos de extrativismo revelam, de forma sintomática, esse processo estrutural internacionalmente instalado, a partir de três episódios da história brasileira.

\section{UMA DISCUSSÃO HISTÓRICA, INERENTE À HUMANIDADE E QUE SE PARTICULARIZA NO CAPITALISMO}

A primeira das considerações que devemos ter em conta é que, pautando-nos no reconhecimento de que o elemento que distingue os seres humanos dos demais animais é o exercício do trabalho (MARX, 2013), e que este "dispêndio produtivo de cérebro, músculos, nervos, mãos etc. humanos" (MARX, 2013, p. 121) orginalmente se volta à produção de valores de uso ${ }^{1}$, o extrativismo acompanha a trajetória humana. Sejam mais

\footnotetext{
É indiscutível que a elaboração da categoria de "valor de uso" goza de historicidade específica - capitalista por excelência, não por outra razão esteja sua mais bem-acabada formulação em O Capital, de Marx (2013) - e a utilização em contextos pré ou pós capitalistas pareceria, à primeira vista, imprópria. Temos em conta, todavia, que as formas sociais se constituem em processos históricos. Daí que em contextos pré-capitalistas muitas das formas sociais típicas e maturadas no âmbito da sociedade da mercadoria gozavam de uma protoconstituição. A mercadoria expressa sintomaticamente esta constatação: existindo de forma marginal e embrionária nas sociedades précapitalistas europeias, assumiu centralidade estrutural apenas com hegemonização da relação social do capital nesta realidade históricosocial (MANDEL, 1962, p.52-81). Deste modo, usar a categoria "valor de uso" desconectada historicamente do "valor de uso capitalista" e do imperativo da uniformização do trabalho abstrato pelo "valor", reconhecendo seu desenvolvimento como precedente às demais categorias próprias da Crítica da Economia Política, nos leva não só a afirmar sua transhistoricidade, como também a perceber sua força transgressora, haja vista que, ao expressar a consecução dos mais genuínos interesses humanos pelo trabalho, tensiona a dominância do capital e suas forças reificadoras (MARX, 2013; LUKÁCS, 2003). Este papel transgressor e inerentemente anticapitalista é o que define sua concepção originária, indissociavelmente ligada à noção de trabalho, que reivindicaremos nas próximas páginas como chave fundamental à estruturação de um arranjo produtivo de caráter ecossocialista.
} 
ou menos impactantes, sejam compatíveis ou não com o metabolismo da natureza não humana, as ações decorrentes do trabalho e a atenção das necessidades de reprodução da vida humana reclamaram atividades extrativas.

A simples coleta de frutos, a utilização de galhos mortos, a derrubada de árvores para realização de abrigos, a caça, o inicial e esporádico lascar de pedras para realização de ferramentas, são exemplos de atividades de natureza extrativa. Não se resumem os atos extrativos, pois, a grandes atividades minerárias, petroleiras ou a processos de destruição florestais, que invariavelmente surgem em nossas mentes à primeira menção do extrativismo. Desse modo, é fundamental ter em conta que as atividades extrativas assumem qualidades e volumes distintos, a depender de sua natureza e funcionalização, que se encontram intimamente ligadas às necessidades individuais humanas, às demandas sistêmicas dos modos de produção e à potência e qualidade das forças produtivas.

Ocorre que por milênios a relação estabelecida entre a humanidade e o restante da natureza pautou-se pela harmonia e equilíbrio na sua reprodução comum - salvo exceções, como é o caso da civilização Rapa na Ilha de Páscoa (WRIGHT, 2007). Mesmo sabendo que alguns processos de trabalho e produção em sociedades pré-capitalistas tenham resultado em diversos impactos ambientais - não só o exemplo supracitado, mas também a própria realidade da Europa Ocidental no medievo demonstra isso, uma vez que a ação humana implicou desarmonias na relação homem-meio ambiente, ensejando pestes, ondas de fome e desabastecimento (LJUNGQVIST et al., 2018) -, passou-se a experimentar uma viragem abrupta no impacto destrutivo do metabolismo humano com a natureza a partir do momento em que as cadências de produção deixaram de ser funcionalizadas pela atenção das necessidades vitais humanas e comunitárias, autodeterminadas por seus imediatos interesses - ou então por classes proprietárias com patamares baixos de acumulação e dispêndio de riquezas - para um arranjo produtivo pautado pela mercadoria.

Expressa de melhor modo na abordagem de Marx (2013) ao fetiche da mercadoria, a submissão humana ao domínio mercantil - que passa a assumir o papel de sujeito no processo de produção, reduzindo homens e mulheres à condição de seus meros objetos portadores e consagradores de seu modo de circulação (BENSAÏD, 2011, p. 55-68) - resulta em processo de domínio crescente e destrutivo do meio ambiente, afrontando brutalmente a situação de relativa harmonia estabelecida entre a sociabilidade humana em seu metabolismo com a natureza.

Certamente essa tônica não se institui da noite para o dia, ou de modo uniforme em todo o planeta. A instalação de formas tipicamente capitalistas de produção e sociabilidade passam a se experimentar paulatinamente nas mais diversas realidades histórico-sociais, tendo a sua marcação originária dada na Europa Ocidental, e, só depois, afirmando-se mundo afora. Ainda, todavia, que não existentes relações sociais essencialmente capitalistas - fundamentalmente pautadas pelo apartamento de produtores dos meios de produção e exploração dos primeiros pela forma do assalariamento -, também na periferia da ordem passam a se estabelecer relações econômicas e sociais não capitalistas funcionais à acumulação originária de capitais (LUXEMBURG, 1976). É o que se percebe, por exemplo, pela dinâmica colonial, em que formas servis, escravocratas e protossalariais, combinam-se à tônica cadenciada por um capitalismo típico concentrado em algumas poucas metrópoles, conferindo à relação social do capital vigor necessário em seu momento germinal.

A atividade extrativa, porém, assume conformações que são distintas nesses dois espaços geopolíticos - metrópole e colônia. No centro e na periferia da ordem produtiva a extração desenha-se com qualidades distintas de intensidade e violência para com o meio ambiente, proporcionados à semelhança da intensidade e violência perpetrados em face de trabalhadores e trabalhadoras que lá são explorados.

Ocorre que o papel das atividades extrativas no capitalismo dos países centrais desta ordem se deu marcada pelo assalariamento, sendo o exemplo do carvão mineral na consolidação industrial emblemático neste sentido (MALM, 2016). Assim, ainda que sujeitando trabalhadoras e trabalhadores - minerários e outros - a péssimas condições de vida, estas não guardam paralelos com as afrontas à humanidade perpetradas ante as pessoas escravizadas que se empenharam no trabalho minerário em toda América Latina, inclusive no Brasil. A coisificação, as péssimas condições de trabalho e a interdição estrutural das formas de consciência e mobilização de classe, assumiram papel ainda mais vultuoso em nossa realidade, trazendo consequências até hoje ao processo de luta de classes e organização das relações de trabalho no contexto latino (GALEANO, 2014, p. 54-60, 77-86, 181-228). 
Temos em conta, porém, que, se de um lado a sanha de afirmação universal do capital passa a ensejar a dissolução das relações de produção de natureza pré-capitalistas, que passam a ser substituídas por relações tipicamente capitalistas, ou seja, marcadas pelo assalariamento, de outro esta afirmação não se dá de forma consciente pelas classes proprietárias do centro e da periferia da ordem do capital, mas, sim, provocada pelas conflitos de classe impulsionados pelos setores explorados e oprimidos da sociedade, levando ao abandono das antigas formas de dominação e conformando as capitalistas, mais complexas em sua dominação e mais profundas na predação de energias humanas e riquezas naturais.

\section{SINGULARIDADE PERIFÉRICA BRASILEIRA E A MINERAÇÃO}

O caso brasileiro é emblemático nesse tocante, e expressa em concreto a tendência sinalizada anteriormente. Tendo a economia colonial pátria assentado-se na exploração do trabalho de pessoas escravizadas em sua maioria sequestradas do continente africano e, em escala bem menor, composta por povos originários americanos - e se voltado à produção destinada ao mercado externo, só foi suplantada após séculos de incansáveis rebeliões das senzalas (MOURA, 1981). Estas foram as determinações fortes que levaram a cúpula das classes dominantes a ceder a abolição da escravatura - formalmente instituída em 13 de maio de 1888, mas materialmente apenas aprofundada nesse momento, uma vez que previamente iniciada e que permanece em curso até os dias de hoje -, passando a constituir um mercado de trabalho no país, isso sem não antes viabilizar, por meio da Lei de Terras de 1850, a interdição do acesso aos meios de produção aos libertos, mostrando que seria apenas pela compra e venda que qualquer parcela de solo nacional poderia ser transferida e incorporada ao patrimônio.

Esse processo social da abolição da escravatura, de caráter revolucionário, ensejou não só uma viragem nas relações de produção estabelecidas no país, inflexionando as formas sociais dominantes, mas em uma mudança do locus de extração de mais-valia resultante da produção de mercadorias no território brasileiro, esta desde 1500 atrelada à conformação da relação social do capital na metrópole. Entendemos que, se de um lado a funcionalização capitalista do escravismo brasileiro teve papel relevante na acumulação originária de capitais, de outro também as mercadorias aqui produzidas ${ }^{2}$ por pessoas escravizadas - madeiras, açúcar, café e, como não poderia deixar de ser, minérios - ensejaram a constituição de capitais pela via mercantil e otimizaram a troca das demais mercadorias na realidade europeia, inclusive pelo uso de ouro e prata como moedas, alavancando potencialmente as primeiras relações de exploração do trabalho pelo assalariamento ao se combinar com o processo de despossessão das parcelas trabalhadoras nas metrópoles.

Com a abolição formal da escravatura no Brasil, o processo de exploração do trabalho assalariado passa a se avolumar em nosso território, isso nos mais diversos espaços da produção (agrícola, majoritariamente) e serviços. A produção minerária, também nesse momento, segue como uma das mais relevantes no campo da produção nacional, não perdendo o vulto que constituíra no curso do século 17 , fundamentalmente nas Minas Gerais. Nada se altera, porém, no andar de cima, posto que no contexto pós-abolição formal e de consolidação republicana (militar) primeva, atrelamento advindo do texto constitucional de 1891 (artigo 72, parágrafo 17ㅇ), da propriedade das minas à do solo, que sedimenta e perpetua as classes proprietárias do país, descolando os produtores - ou seja, os trabalhadores e trabalhadoras da mineração - dos meios de produção também no que se refere ao processo produtivo minerário.

Ainda que se verifiquem mudanças na natureza das relações de trabalho, não há flexão dos sujeitos que gozam dos produtos da mineração, tampouco alteram o lugar do Brasil na DIT, com o papel da economia brasileira pautada por seu sentido colonial voltado à exportação de seus produtos (PRADO JÚNIOR, 2000). Este sentido, bem sabido, guarda, para além de um conectivo com as atividades agrárias, profunda ligação com as atividades extrativas, tanto minerais quanto vegetais, que serviram de alicerce aos primeiros ciclos de atividade econômica no país, e seguem, contemporaneamente - a elas se atrelando as petrolíferas -, como carros-chefes da economia brasileira de padrão exportador, em processo de reversão colonial acentuado (SAMPAIO JÚNIOR, 2007).

\footnotetext{
Não se pode perder de vista que as atividades de trabalho empenhadas por pessoas escravizadas no curso dos séculos 16 a 19 no Brasil, não se limitavam a ações produtivas, existindo um vasto contingente de trabalhadoras e trabalhadores que se ativavam em atividades reprodutivas, isso no empenho das mais diversas tarefas no lar senhorial, ou mesmo no fomento à existência das populações escravizadas.
} 
Percebemos, assim, que uma série de chagas que se ligam ao período da escravidão legal no país, sobretudo naquilo que se refere ao trato da mineração, não tiveram substantivas mudanças após a abolição. Não só afirmamos isso no que se refere a aspectos estruturais: quando olhamos para a mentalidade condescendente à descartabilidade da vida das pessoas trabalhadoras, promotoras de condições inseguras e ofensivas à saúde de quem trabalha, assim como de completo descaso para com o meio ambiente - donde os recentes desastres em Mariana e Brumadinho, em Minas Gerais, são grandes exemplos -, percebemos a manutenção deste estado de coisas.

Estes traços, porém, não caminham em sentido necessário, sem comportar tensões e alterações de ordem prática relevantes. A constituição do Direito Social (CESARINO JÚNIOR, 1943) no Brasil demonstra como, em parte, ainda que sem impacto estrutural, alguns traços dessa tradição dos vencedores foram flexionados e torcidos. Diz-se isso em razão de que a organização do mercado de trabalho no Brasil não teve apenas na Lei de Terras e na Lei Áurea suas peças-chave constitutivas. A formação de uma legislação trabalhista - de início esparsa, e posteriormente arranjada na Consolidação das Leis do Trabalho - cumpre papel fundamental não só na constituição desse mercado (BARBOSA, 2008), mas no modelar da acumulação capitalista no Brasil (OLIVEIRA, 2003). Constituídas por um complexo processo de enfrentamento de classe a acomodação conciliadora pelas classes proprietárias, tais leis expressam a correlação de forças da luta social no país.

\section{REGULAMENTAÇÃO DA EXPLORAÇÃO E LUTA DE CLASSE ENTRE CENTRO E PERIFERIA: Elementos Para Compreensão de uma Divisão Internacional do Direito do Trabalho}

Pensar a composição do Direito Social no Brasil é ter em conta que este se expressa, como todo construto concreto - a que a juridicidade não deixa ser exemplo (PACHUKANIS, 2017) -, como uma síntese de múltiplas determinações (KOSIK, 1969).

Ainda que a historiografia clássica relacionada ao referido campo do direito coloque em conta papéis ideológicos e institucionais como suas principais referências constitutivas - vide o vulto conferido à Doutrina Social da Igreja Católica Apostólica Romana, fundamentalmente após a Encíclica Rerum Novarum, de 1891, e à criação da Organização Internacional do Trabalho, em 1919 (SEFERIAN, 2019 , p. 14) -, tomar a leitura do Direito do Trabalho (e do Direito Social em geral) desde um registro materialista dialético impõe levar em conta que a fundamental força constitutiva deste campo do direito - assim como de todos os demais - é a luta de classes. Logo, é a ofensiva das classes trabalhadoras ante os interesses das classes exploradoras que enseja a criação deste repertório normativo, uma vez que as últimas, sem outras alternativas perante a pressão política dos oprimidos e oprimidas e na desesperada busca pela manutenção de seu poderio econômico, cedem os anéis para não perder os dedos (RAMOS FILHO, 2012), admitindo torções nos referenciais tradicionais da juridicidade para salvaguardar às classes trabalhadoras renda, tempo livre e melhores condições de saúde, segurança e higiene no labor.

A constituição desse arcabouço de Direitos Sociais encontra, porém, modulações diversas, marcadas, de um lado, pelo desenvolvimento desigual e combinado do modo de produção capitalista (TROTSKY, 2007, 2011), e, de outro, pelo distinto arranjo que as sociedades de classes estabelecem, constituindo e definindo seu próprio fazer histórico. Em outras palavras, em como nestas diversas realidades se instituem as lutas de classes.

Sabemos que nesse desenvolvimento desigual e combinado, e tomado o modo de produção capitalista enquanto um sistema mundial uno, centro e periferia da ordem produtiva capitalista estabelecem relações dialéticas e condicionadas. Global desde suas origens, o modo de produção capitalista vê aprofundada essa articulação centro-periferia com os adventos tecnológicos utilizados nos processos de produção, comunicação e transporte experimentados nos últimos séculos. Daí que centro e periferia não se esgotam em metrópole e colônia. Estes se reinventaram e reinventam. Não por outra razão, dirá Daniel Bensaïd (1997, p. 19) que vivemos um momento em que as mudanças de escala e alterações de ritmo nos levam à vertigem. $O$ trato da questão territorial no cerne das sociedades capitalistas assume novas cores e características sobretudo com o desenvolvimento urbano, a recomposição dos Estados nacionais e a particularização das atividades econômicas em territórios específicos. 
Essa costura enquadra-se no registro categorizado por Marx enquanto divisão social do trabalho, que assume historicamente diversos contornos e formações, bem como intensidades diversas. Atravessadas por marcadores de gênero, raça, etnia, sexualidade, origem nacional e outros, assume destaque aos nossos olhos quando tocado por aspectos de ordem territorial, dando os contornos da DIT. Constituída dentro dos marcos do já mencionado desenvolvimento desigual e combinado do capitalismo na ordem global, esta dará o tom às diferenças existentes entre os graus de exploração, a natureza das atividades econômicas, o direcionamento da produção social, a forma como se estabelecem as relações de produção, a intensidade da violência para com a natureza, entre outros tantos fatores, conferindo funcionalidade ao território para modulação de afirmação do domínio mercantil e o processo de extração do mais-valor.

Enseja a DIT, por exemplo, um espaço originariamente voltado à produção de bens primários na periferia colonial/imperializada da ordem, e outro à produção industrial no centro metropolitano/imperialista. Viabiliza, com o desdobrar da afirmação capitalista, o desenvolvimento da grande indústria nos países centrais e o alicerçar de um projeto de industrialização dependente - tecnológica e economicamente - para com os países dominantes (MARINI, 2000). A forma como as relações de trabalho se estabelecem - mesmo em ramos de atividade econômica idênticos - e o descaso com a natureza, acompanham estas variações postas em contextos distintos. É o caso da mineração, que nos serve como um dos principais objetos de reflexão em se tratando de modo de trabalho extrativo.

Remetem as historiografias tradicional e crítica, bem como a memória operária e os monumentos da cultura ocidental a um cenário de atrocidades praticados contra os trabalhadores do setor minerário na origem dos processos de industrialização europeias, sobretudo quando olhamos as atividades ligadas ao carvão. Lembram o quanto os acidentes eram cotidianos e a sujeição a condições degradantes não fazia distinção etária ou de gênero. Certo, porém, é que na realidade dependente e periférica brasileira - bem como no restante da América Latina, a exemplo dos territórios que hoje constituem a Bolívia, Chile, México e Peru - tais circunstâncias se mostravam, e mostram, ainda mais daninhas às condições de vida da população que trabalha.

Tal se diz, de um lado, dado o condicionante histórico marcado pelo trato da coisificação radical dos trabalhadores e trabalhadoras proporcionado pela escravidão, fato que por si só estruturalmente impunha um forte peso de descaso à condição de humanidade destas pessoas, sujeitando-as à penúria, sobrecarga e perigo que extrapolavam os limites considerados moralmente toleráveis a iguais. Estas marcas, arraigadas culturalmente nas práticas das classes proprietárias de nosso país até hoje - já que herdeiras, como benjaminianamente não podemos negar, das classes dominantes e escravocratas de outrora (LÖWY, 2005, p.80) -, no processo de constituição do mercado de trabalho brasileiro seguiram em larga medida presentes, condicionando as práticas de trabalho e a sujeição a péssimas condições de labor ao conjunto das classes trabalhadoras, não sendo exceção aquele estrato composto por trabalhadores e trabalhadoras da mineração.

Essa característica, que serve de marca à superexploração que dá o tom ao assalariamento no Brasil (MARINI, 2000), estreita as perspectivas de vida - tanto em sua qualidade quanto no que se refere à longevidade - de quem trabalha em nossa Pátria Grande, sobretudo no trabalho extrativo, donde o caso da mineração é exemplar: para nos atermos a um único indicador, os riscos de desenvolvimento de neoplasias é acentuadamente maior para as pessoas que trabalham em minas quando comparado com o restante da população (VERÍSSIMO et al., 2013), e o principal motivador deste estado de coisas é ambiental.

Ademais disso, a precedência cronológica da forma de exploração assalariada no contexto europeu despertou, em caráter mais ancestral, a confirmação das tendências postas à auto-organização das classes trabaIhadoras modernas, pari passu ao processo de concentração obreira nas unidades produtivas (sejam fabris, sejam extrativas). Esse fato resultou na estruturação de mecanismos de resistência e reivindicação mais precocemente, viabilizando um arcabouço protetivo a esse conjunto da população trabalhadora e a estruturação de uma cultura de mobilização sindical densa, trazendo melhorias ímpares das condições de trabalho, mas tardiamente experimentadas no Brasil.

O exemplo histórico do sindicalismo dos mineiros na Inglaterra é gritante nesse sentido (TUC, 1947), tendo sido este só desmontado e desmoralizado - ainda que interpretações diversas pairem sobre tais eventos - com a ofensiva neoliberal capitaneada por Margareth Thatcher após a heroica greve conduzida entre 1984 e 1985 (DARLINGTON, 2005). Essa modulação clássica que leva à estruturação do Direito do Trabalho nos países centrais da ordem capitalista, que historicamente alçou pautas ambientais - de condições de vida, 
saneamento e saúde no espaço do trabalho - e que contou com a atuação de trabalhadoras e trabalhadores do setor minerário desde os seus passos fundantes, segue cadência muito particular em nossa realidade dependente e periférica.

Da mesma sorte que o processo de afirmação capitalista se pauta desde as particularidades histórico-sociais de cada região do globo para se instalar, também a luta sindical e a organização dos mais diversos setores das classes trabalhadoras passa por esse processo. Gozando estes fenômenos sociais de historicidade específica, tanto o sindicalismo quanto a conformação do Direito do Trabalho terão modulações ditadas pelas características que o modo de produção assumirá nos diversos rincões do globo, dadas as distinções no processo de acumulação existentes em cada uma dessas territorialidades pautadas pela DIT.

Assim, se no Brasil o assalariamento só passa a se generalizar após a abolição formal da escravatura, o sindicalismo como forma de luta acaba por retardar seus primeiros passos quando comparado com os países do centro da ordem capitalista, que já, há um século, experimentavam essa forma social, sendo tardia também a constituição do Direito do Trabalho no país.

O caráter tardio é apenas uma das características do Direito do Trabalho no Brasil, mas outras tantas particularidades lhe são próprias. É nesse processo de constituição juslaboral, que guarda semelhanças e distinções com o Direito do Trabalho posto nos países centrais da ordem, que reconhecemos não só o desenvolvimento desigual e combinado do Direito do Trabalho, mas também o seu instalar em uma divisão internacional do Direito do Trabalho.

A referida divisão internacional operacionaliza-se, de um lado, pela funcionalização das relações econômicas globais desde o registro territorial, que reclamará que em alguns rincões do planeta a lógica de assalariamento se mostre mais violenta e predatória do que em outras; isso tanto no que se refere à matéria remuneratória - sobretudo por não se reclamar destes trabalhadores e trabalhadoras o consumo daquilo que por eles é produzido e, invariavelmente, exportado aos países centrais da ordem -, quanto no que diz respeito às condições gerais de saúde, higiene e segurança do trabalho - proporcionando uma redução da expectativa de vida dos trabalhadores e trabalhadoras, e que guarda direta relação com as condições ambientais em que a vida se reproduzirá, inclusive no trabalho. Daí Ruy Mauro Marini (2000) definir a superexploração como sendo o processo em que ocorre "maior exploração da força física do trabalhador, em contraposição à exploração resultante do aumento de sua produtividade e tende normalmente a expressar-se no fato de que a força de trabalho se remunere por baixo de seu valor real" (p. 160).

Isso aponta para uma objetiva necessidade de, na realidade periférica e dependente do capitalismo, constituir-se um Direito do Trabalho de menor intensidade, menos vigoroso pela própria viabilidade econômica da superexploração? Não, em absoluto. Trata, no entanto, de uma barreira estrutural rígida a impedir sua efetivação, fato que confere também aos marcos protetivos do Direito do Trabalho nestas realidades, muito mais difíceis de se efetivar, um papel de tensão antissistêmica mais agudo.

Afirmamos isso em razão de a economia ser apenas uma das determinações que condicionam a constituição juslaboral, incidindo outras tantas na sua concreta delineação. A principal delas, não há que se questionar, é justamente a política. É no bojo do processo da luta de classes, instalado nos mais diversos e particulares desenhos da sociedade capitalista, que as pressões dos de baixo se conformam, institucionalmente e com vistas de pacificação social, em Direitos do Trabalho de "calibres" diversos.

Com estes dois fatores - econômico e político - encontra-se outro de suma relevância aos nossos olhos, que é o ambiental. Posto justamente ante o descompasso do metabolismo humano com as temporalidades dos processos da natureza não humana, é certo que a produção e consequente distribuição de riquezas é condicionada por essa barreira objetiva que não pode ser desconsiderada, ainda mais ante o cenário de crise civilizacional de nuances ecológicas sem precedentes em que vivemos (LÖWY, 2013). Não por outra razão, a ponderação trazida por Razmig Keucheyan (2018) acerca do reconhecimento contemporâneo da dialética entre senhor-escravo-natureza, seja de todo pertinente, prenunciando a natureza como um campo de batalha classista.

Em síntese apertada, são as pressões da luta das classes trabalhadoras que levam as classes proprietárias, investidas de poder político e instaladas no Estado, a ceder suas ganas exploratórias e constituir instrumentos jurídicos que proporcionem condições efetivas de existência às pessoas que trabalham, tanto para fins de renda quanto para condições de harmonia ambiental. É desse processo que se forjam os Direitos Sociais. 
Tomando a luta do proletariado (BENSAÏD, 2008, p. 36-39), esse desenho protetivo, voltado às relações de trabalho, é o juslaboral, que leva à proteção de quem trabalha em sua relação com quem explora. Esta é a essência do Direito do Trabalho e sua dinâmica básica de conformação. O quanto e como cedem as classes proprietárias nos diversos Estados nacionais, todavia, variará conforme o papel econômico que cumprem na DIT, bem como de sua força política.

Assim, o Direito do Trabalho no Brasil é distinto daquele existente nos países centrais da ordem, ainda que este Direito do Trabalho guarde alguns elementos de identidade essenciais. Sua distinção é servil, historicamente, à manutenção do Brasil em seu locus dependente e periférico na economia capitalista, inclusive viabilizando o perdurar das práticas de superexploração e interdição da auto-organização das trabalhadoras e trabalhadores por meio de mecanismos políticos violentos, antidemocráticos e ecocidas.

\section{O TRABALHO NA MINERAÇÃO ONTEM E HOJE NA CONSTITUIÇÃO DA REGULAMENTAÇÃO DA CONTRATAÇÃO DA FORÇA DE TRABALHO NO BRASIL}

Saindo do sobrevoo categorial, o repertório historiográfico nos leva a verificar como as tendências de conformação do Direito do Trabalho assentam-se em nossa realidade, conferindo lastro às nossas proposições. O trabalho extrativo minerário nos serve de importante manancial para tais reflexões, posto que teve um papel decisivo na conformação da regulamentação da contratação da força de trabalho no Brasil. Afinal, as lutas das pessoas que trabalham na extração minerária tiveram parte decisiva em nossa história política.

Dada a dimensão e natureza deste texto, buscaremos sinalizar o papel da luta de classes decorrente do trabalho extrativo minerário na formação juslaboral brasileira desde três experiências episódicas. Sintomaticamente, expressam estes momentos não só etapas decisivas do enfrentamento de classe no país, mas também o papel da economia brasileira no capitalismo globalizado e indissociável vinculação da luta de classes com a questão ecológica.

A primeira delas liga-se ao período escravocrata. Como mencionamos alhures, o processo de abolição formal da escravatura no nosso país foi impulsionado por profundas lutas e insurreições conduzidas por pessoas escravizadas. A memória dos quilombos e o processo de constituição do quilombismo (NASCIMENTO, 2002) são basilares nesta resistência que impôs às mãos brancas de Isabel a assinatura da Lei Áurea.

Desde o início da colonização, a existência política das negras e negros sequestrados do continente africano mostrava-se incompatível com a conformação do capitalismo à brasileira. Primeiramente, diante da lógica predatória, violenta e coisificadora que cadencia a acumulação primitiva de capitais, encontrando no corpo das pessoas escravizadas sua fronteira última e sua resistência primeira, e, em um segundo momento, ante as disposições de instituição do assalariamento no país como uma consequência dos ideais liberais burgueses europeus, que, ao menos no discurso (BENSAï̄, 1989, p. 52), reclamavam a abolição formal da escravatura.

As contradições e tensões postas nas relações de trabalho por estas ideias fora do lugar (SCHWARZ, 1992) aprofundaram na nossa realidade dependente e periférica a dualidade de interesses entre classes proprietárias e trabalhadoras, que não precisou esperar até o início das políticas públicas de branqueamento do mercado de trabalho (SOUTO MAIOR, 2017, p. 104-113) para irromper, manifestando, já em seus primeiros passos, na experiência dos inconfidentes, forte expressão. É o que percebe Clóvis Moura (1981, p. 58), atento à produção minerária:

Tiradentes, segundo Norberto de Souza Silva, chegou a possuir três escravos nas suas malogradas tentativas de mineração. O certo é que pelo menos uma escrava sabemos ter pertencido ao Alferes Inconfidente: a que foi doada por ele a D. Maria do Espírito Santo, órfã menor a quem Tiradentes deixara grávida "com promessas esponsalícias" e de quem tivera uma filha.

As tensões não se limitavam ao campo da coerência das ideias. O espaço da mineração não foi isento de intensas tensões e lutas classistas. Tratando das Minas Gerais, o mesmo Clóvis Moura (1981, p. 92) aponta como exemplo: 
Os quilombolas se aliavam aos contrabandistas de diamantes e serão uma preocupação constante; muito trabalho darão aos dirigentes da Capitania. Segundo um historiador dessa região - M. M. de Barros Latif - em consequência das facilidades que os escravos encontravam para a fuga na mineração, a repressão se processará com mais vigilância em Minas Gerais de que nas demais capitanias, tendo, mesmo, as cadeias, públicas se transformado nos edifícios mais importantes das cidades, vilas e povoados mineiros; importância que advinha da vigilância repressiva movida pelo governo, repressão tanto mais acentuada quanto era o interesse da Metrópole em arrancar as riquezas do subsolo mineiro. Durante muito tempo viveu no distrito diamantino um legendário negro chamado Isidoro, conhecido posteriormente por "O Mártir", que durante anos atuou à frente de 50 quilombolas, praticamente invencível até a morte, no ano de 1809.

O destrutivo caráter do processo de acumulação primitiva de capital, que se volta contra a vida de trabalhadoras e trabalhadores escravizados, também se direciona à natureza. Em relato de 1830, o botânico Auguste de Saint-Hilaire não podia deixar de observar a miséria em que vivia a população de Ouro Preto, e, por dever de ofício, os impactos ambientais das atividades extrativas. Olhando para os "dois morros que avançam pelo vallão de Rio d'Ouro Preto", percebeu que "deixam entre elles, em um plano pouco menos saliente, um espaço triangular sem cultura e habitação, onde o terreno revolvido e despojado de vegetação deixa por toda a parte lobrigar vestígios afflictivos dos trabalhos dos mineiros" (SAINT-HILAIRE, 1938, p. 132). E arremata, com aguda percepção ecológica:

os actuaes habitantes de Minas Geraes, tão imprevidentes como seus antepassados e mais culpáveis ainda, pois que já sentem os efeitos do mal, os habitantes actuaes de Minas Geraes, digo, contuam a destruir insensatamente suas mattas, e deixarão a seus descendentes uma situação mais lastimável ainda que aquella cujos efeitos já experimentam (SAINT-HILAIRE, 1938, p. 176).

Ainda que largamente indocumentados - sobretudo por conta da Lei de 13 de maio de 1891, capitaneada por Ruy Barbosa, que pôs fim com fogo a documentos da memória da escravidão -, os exemplos mencionados anteriormente denotam sintomaticamente a presença destes conflitos, como o ambiente da mineração, que não se via isento destas contradições, e a luta insurrecional da negritude brasileira, desde seu gérmen, que era incompatível com as pálidas teorias de liberdade formal pautadas pela intelectualidade burguesa ou aburguesada do país, servindo de passo primeiro à conformação de nosso Direito do Trabalho e da revolução brasileira.

A segunda experiência situa-se no desfecho do último ciclo do grande processo de conformação do Direito do Trabalho brasileiro, que, irrompendo com a formação de um mercado de trabalho no país, passa a ser minado após o processo contrarrevolucionário preventivo instalado com o golpe empresarial-militar de 1964. Voltaremos nossos olhos ao processo de luta e auto-organização dos trabalhadores e trabalhadoras do cimento e cal de Perus, Bairro de São Paulo, que constituíram aquele que ficou conhecido como "Sindicato dos Queixadas".

Sabemos que o Direito do Trabalho se constitui no Brasil desde a Primeira República impulsionado pelo desespero das classes proprietárias ante as lutas revolucionárias de anarquistas e socialistas europeus - como conta a historiografia tradicional -, potencialmente combinadas com a sabedoria insurrecional da negritude recém-liberta no país (GÓIS, SEFERIAN, 2017). Esse conjunto de proteções normativas, de início particularizadas a algumas unidades produtivas ou setores das classes trabalhadoras, e que depois foram instituídas em leis esparsas com abrangência a todo contingente proletário, servirá de base a Getúlio Vargas para a promulgação da Consolidação das Leis do Trabalho, operacionalizando o "roubo da fala" dos trabalhadores (PARANHOS, 1999) por intermédio da ideologia da outorga (VIANNA, 1989, p. 87-152).

Notamos que desde o curso da Primeira República, adentrando a ditadura varguista em suas diversas expressões, e, posteriormente, no curso da Segunda República brasileira, que vai até 1964, o arcabouço protetivo juslaboral apenas se aprofundou, isso em razão do processo de ofensiva das classes trabalhadoras, não obstante os esforços para pacificação da conflituosidade de classes no país. Parte substanciosa desta última onda ofensiva - dada nos anos 1950 e 1960 - teve palco nas atividades de mineração, quando a luta do "Sindicato dos Queixadas" assume grande importância. O movimento, síntese de uma articulação que não só contemplava os trabalhadores da empresa, mas também toda a comunidade do entorno da mineradora como intelectuais, religiosos, familiares, moradores e comerciantes do Bairro de Perus -, trouxe novos ares à construção de forças insurrecionais na órbita do sindicalismo e na busca de direitos para as trabalhadoras e trabalhadores. 
De forma original, o "Sindicato dos Queixadas" articulou demandas que exorbitavam o corporativismo profissional - lutando por pautas econômicas transcategoriais ou classistas, a exemplo do enfrentamento travado nos anos 1950 em que buscavam ou o aumento de seus salários ou a redução do preço do cimento, para viabilizar acesso ao produto pelos trabalhadores que construíam suas casas -, empenhou-se em bandeiras de caráter fortemente antissistêmico - ao problematizar a gestão fabril, batalhando pela expropriação do capitalista J. J. Abdalla e buscando sua autogestão operária -, construiu métodos de luta inovadores - como a afirmação da chamada "firmeza permanente", inspirada nas lutas pacifistas de Gandhi e outros movimentos pelos direitos civis - e encampou pautas até então jamais animadas por movimentos sindicais do país - como foi o caso das reivindicações de caráter ambiental direcionadas ao seu empregador, que transbordavam a vivência na fábrica, alcançando não só a vizinhança da planta mas toda a sociedade (JESUS, 1992).

Quanto a esse particular aspecto ambiental das mobilizações, há de se ter em conta que o crescente papel da indústria, a que se ligavam tais trabalhadores, acompanhava a demanda de cimento em São Paulo e em todo país, pautada pela ampliação da população urbana nacional. Isso foi o incremento produtivo, acompanhado da minoração de gastos com elementos aptos a conter a emissão de poluentes, que resultou as diversas marchas organizadas por trabalhadores do cimento e cal de Perus junto a seus familiares, buscando a construção de filtros nas chaminés da fábrica bem como outras medidas voltadas à melhoria das condições de trabalho e vida nos arredores da empresa (ALVES, 2011, p. 27), uma vez que era insustentável a vida assolados por "uma fumaça turva, carregada de pó de cimento, que se depositava nos telhados dos moradores" (MOREIRA; GOULD, 2013, p. 15). O "Sindicato dos Queixadas", que guardava uma íntima ligação com o cristianismo da libertação (LÖWY, 2016), acabou por impulsionar outras tantas lutas ambientalistas de caráter mais amplo, inclusive a Campanha da Fraternidade de 1979 com o lema "Preserve o que é de todos", muito embora já desde 1973 - ano em que as mobilizações atentas a pautas ambientais dos Queixadas se iniciaram - entoasse, em algumas medidas, chamados ecológicos (NANDI, 2015).

Por fim, é de se colocar aqui o papel da luta dos petroleiros e petroleiras no curso dos anos 90 . Em um contexto de fragmentação do paramento juslaboral, conquistado até 1964, os anos que sequenciam a redemocratização formal do país são marcados por uma ofensiva de matriz neoliberal que projeta a diversos setores das classes trabalhadoras seus ataques. Aos petroleiros e petroleiras, o obus teve múltiplas intencionalidades: não só serviu para promover a privatização da Petrobras, como - mais grave - visou a debelar uma das organizações sindicais mais fortes do país, atingindo, com isso, o conjunto de outras entidades de classe, abrindo margens para a reorganização produtiva que nos anos subsequentes se instituiu em profundidade no país.

A resistência dos petroleiros e petroleiras foi imensa, articulando uma greve sem precedentes. A ação articulada do grande capital, porém, mediada pelo Poder Judiciário e as Forças Armadas, impôs uma pesada repressão à Federação Única dos Petroleiros, levando à ocupação militar de refinarias de petróleo e à declaração de abusividade da greve, impondo severas multas não somente às entidades representativas dos e das grevistas, mas também àqueles sindicatos que se solidarizaram com tal luta (CORREGLIANO, 2014).

As medidas flexibilizadoras de direitos trabalhistas que se estabeleceram em todo país nos anos 1990, vêm acompanhadas do aprofundando da dependência energética para com fontes fósseis (TOLMASQUIM et al., 2007, p. 55-58), fortalecendo a indústria petrolífera e o conjunto de atividades econômicas dela dependentes, intensificando a emissão de hidrocarbonetos. Esse fato alia-se a outras medidas introduzidas pelo setor do petróleo que, com vistas à ampliação das margens de lucro de seus investidores-acionistas, traz à míngua as políticas de segurança, proporcionando, no período, uma escalada de acidentes, como o naufrágio da Plataforma P-36, em 2001, e outros pequenos acidentes que passam a ser costumeiros a partir de 1997 (BIOMANIA, 2020).

\section{CONCLUSÃO}

Diante do exposto, pudemos traçar um panorama do modo como o Direito do Trabalho constitui-se nas diversas realidades do capitalismo globalizado, tendo em conta fundamentalmente as determinações do desenvolvimento desigual e combinado do capitalismo, a DIT e o processo da luta de classe ínsito aos diversos contextos nacionais. 
O exemplo da realidade brasileira, tomado desde três experiências pontuais, revela não somente que as atividades extrativas dão o tom à economia nacional desde priscas eras, mas também no bojo das relações de trabalho empreendidas na sua condução no processo de enfrentamento de classes - ora pela ofensiva das classes trabalhadoras, ora pela ofensiva das classes proprietárias e dominantes - e se mostra central para a compreensão da regulamentação da contratação da força de trabalho e da cadência de destruição da natureza não humana.

Tomamos aqui como de máxima relevância a permanente atenção ao trabalho extrativo - florestal, mineral, petroleiro e outros - não só por compreendê-lo como central no processo da luta de classes na sociedade do capital, mas também ante a certeza de que são esses os setores das classes trabalhadoras que mais esforços e desafios possuem em sua reinvenção política, sobremaneira ante a convergência de pautas ambientais em suas lutas corporativas, compreendendo que os ataques às classes trabalhadoras no curso de nossa história acabam acompanhados de ataques da mesma sorte contundentes ao meio ambiente.

Novos horizontes políticos colocam-se em um momento histórico em que a crise ambiental avança a largos passos ante a incessante gana produtivista e consumista do capital. A defesa irrestrita de postos de trabalho que fomentam, pela sua própria existência, a destruição do planeta, passa a ser tema de profundas preocupações. A readequação da forma como lidamos com o meio ambiente e como as ofensivas dos trabaIhadores e trabalhadoras devem se articular nesse tocante, despontam como o mais importante desafio do movimento sindical e social nesta quadra histórica.

Particularmente na periferia da ordem, em que as violências trabalhistas e ambientais são ainda mais profundas, essa urgência coloca-se com maior contundência. O Direito do Trabalho brasileiro, que com a Lei n. 13.467/2017 passou por um duro golpe, necessita ser reinventado. Essa reinvenção, para que atenda aos mais radicais interesses das classes trabalhadoras, deve ser ecologicamente determinada e taticamente posta em função de conferir não só melhores condições sociais e econômicas a quem trabalha, mas também saldos políticos para a construção de uma alternativa estratégica revolucionária (e ecológica) sem precedentes.

O planeta pede clemência, e o capital recebe tal pleito com ouvidos moucos. Aos trabalhadores e trabalhadoras do setor extrativo - assim como de outros ramos da produção - cabe a importante tarefa de ouvir estes gritos de agonia e reformular sua ação transformadora.

\section{REFERÊNCIAS}

ALVES, Maria Madalena Ferreira. Mulheres em luta: uma outra história do movimento "Queixadas" de Perus. 2011. Dissertação (Mestrado em Ciências da Religião) - Pontifícia Universidade Católica de São Paulo, 2011.

BARBOSA, Alexandre de Freitas. A formação do mercado de trabalho no Brasil. São Paulo: Alameda, 2008.

BENSAÏD, Daniel. Le pari mélancolique: metamorfoses de la politique, politique des metamorfoses. Paris: Fayard, 1997.

BENSAÏD, Daniel. Le spetacle, stade ultime du fétichisme de la marchandise. Paris: Lignes, 2011.

BENSAÏD, Daniel. Moi, la révolution: remembrances d'une bicentenaire indigne. Paris: Gallimard, 1989.

BENSAÏD, Daniel. Os irredutiveis: teoremas da resistência para o tempo presente. Trad. Wanda Caldeira Brant, São Paulo: Boitempo, 2008.

BIOMANIA. Principais acidentes com petróleo e derivados no Brasil. Disponível em: https://biomania.com.br/artigo/principais-acidentes-com-petroleo-e-derivados-no-brasil. Acesso em: 20 abr. 2020.

CESARINO JÚNIOR, Antonio. Direito social brasileiro. São Paulo: Martins Fontes, 1943.

CORREGLIANO, Danilo Uler. O sistema de controle judicial do movimento grevista no Brasil: da greve dos petroleiros em 1995 aos dias atuais. 2014. Dissertação (Mestrado) - Faculdade de Direito da Universidade de São Paulo, 2014.

DARLINGTON, T. T. There is no alternative: exploring the options in the 1984-5 miners' strike. 2005. Disponível em: https://usir. salford.ac.uk/id/eprint/10099/3/1972_and_1984_Miners\%27_Strikes.pdf. Acesso em: 19 ago. 2019.

GALEANO, Eduardo. As veias abertas da América Latina. Trad. Sergio Faraco. Porto Alegre: LP\&M, 2014.

JESUS, Mario Carvalho de. Cimento Perus: 40 anos de ação sindical transformam velha fábrica em centro de cultura municipal. São Paulo: JMJ, 1992.

KEUCHEYAN, Razmig. La nature est un champ de bataille. Paris: La Decouverte, 2018

KOSIK, Karel. Dialética do concreto. Trad. Célia Neves e Alderico Toríbio. Rio de Janeiro: Paz e Terra, 1969.

LJUNGQVIST, Fredrik Charpentier et al. Linking European building activity with plague history. Journal of Archaeological Science, n. 98, p. 81-92, 2018. 
LÖWY, Michael. Cenários do pior e alternativa ecossocialista. Serviço Social \& Sociedade, São Paulo, n. 104, p. 681-694, out./ dez. 2010.

LÖWY, Michael. Crise ecológica, crise capitalista, crise de civilização: a alternativa ecossocialista. Caderno CRH, Salvador, v. 26, n.67, p. 79-86, jan./abr. 2013.

LÖWY, Michael. O que é cristianismo da libertação? Religião e política na América Latina. 2. ed. São Paulo: Expressão Popular, 2016.

LÖWY, Michael. Walter Benjamin: aviso de incêndio. Uma leitura das teses "Sobre o conceito de história". Trad. Wanda Nogueira Caldeira Brant. São Paulo: Boitempo, 2005.

LUKÁCS, Georg. História e consciência de classe: estudos sobre a dialética marxista. Trad. Rodnei Nascimento. São Paulo: Martins Fontes, 2003.

LUXEMBURG, Rosa. A acumulação do capital: estudo sobre a interpretação econômica do imperialismo. Trad. Moniz Bandeira. 2. ed. Rio de Janeiro: Zahar, 1976.

MALM, Andreas. Fossil capital: the rise of steam power and the roots of global warming. London: Verso, 2016.

MANDEL, Ernest. Traité d'économie marxiste. Tomo I. Paris: UGE, 1962.

MARINI, Ruy Mauro. Dialética da dependência. Petrópolis: Vozes; Buenos Aires: Clacso, 2000.

MARX, Karl. O capital: livro I: o processo de produção do capital. Trad. Rubens Enderle. São Paulo: Boitempo, 2013.

MOREIRA, Jéssica Aparecida; GOULD, Larissa. Queixadas: por trás dos 7 anos de greve, 2013.

MOURA, Clóvis. Rebeliões da Senzala. 3. ed. São Paulo: Lech, 1981.

NANDI, Domingos Volney. Os temas ecológicos nas Campanhas da Fraternidade. Encontros Teológicos, n. 72, ano 30, n. 3, p. 27-36, 2015.

NASCIMENTO, Abdias. O quilombismo. 2. ed. Brasília; Rio de Janeiro: Fundação Cultural Palmares; O.R., 2002.

OLIVEIRA, Francisco de. Crítica da razão dualista - o ornitorrinco. São Paulo: Boitempo, 2003.

PACHUKANIS, Evgeni. A teoria geral do direito e o marxismo e ensaios escolhidos (1921-1929). Coord. Marcus Orione. Trad. Lucas Simone. São Paulo: Sundermann, 2017.

PARANHOS, Adalberto. O roubo da fala: origens da ideologia do trabalhismo no Brasil. São Paulo: Boitempo, 1999.

PRADO JÚNIOR, Caio. O sentido da colonização. In: PRADO JÚNIOR, Caio. Formação do Brasil contemporâneo: colônia. São Paulo: Brasiliense, 2000.

RAMOS FILHO, Wilson. O direito capitalista do trabalho. São Paulo: LTR, 2012.

SAINT-HILAIRE, Augusto de. Viagem pelas províncias de Rio de Janeiro e Minas Geraes. 10 tomo. Trad. Clado Ribeiro de Lessa. São Paulo: Companhia Editora Nacional, 1938.

SAMPAIO JÚNIOR, Plinio de Arruda. Globalização e reversão neocolonial: o impasse brasileiro. In: HOYOS VÁSQUEZ, Guillermo. Filosofía y teorías políticas entre la crítica y la utopía. Buenos Aires: Clacso, 2007.

SARTORI, Vitor Bartoletti.Direito, política e reconhecimento: apontamentos sobre Karl Marx e a crítica ao Direito. Revista da Faculdade de Direito, Curitiba: UFPR, v. 61, n. 2, p. 203-233, maio/ago. 2016.

SCHWARZ, Roberto. As ideias fora do lugar. In: SCHWARZ, Roberto. Ao vencedor, as batatas. São Paulo: Duas cidades, 1992.

SEFERIAN, Gustavo. Direito do trabalho como barricada: sobre o papel tático da proteção jurídica do trabalhador. 2017. Tese (Doutorado em Direito) - Faculdade de Direito da Universidade de São Paulo - USP, São Paulo, SP, 2017.

SEFERIAN, Gustavo. Sobre o uso da miséria historiográfica e a relevância da investigação histórica na aplicação do Direito do Trabalho. Revista da Faculdade de Direito da UFG, n. 43, 2019.

SEFERIAN, Gustavo; GÓIS, Tainã. Os reflexos de quem somos: hipóteses acerca do trato racial e da auto-organização na constituição da classe operária e do direito do trabalho na Primeira República. Revista da Faculdade de Direito da Universidade Federal de Uberlândia, v. 45, n. 1, 2017.

SOUTO MAIOR, Jorge Luiz. Curso de Direito do Trabalho: História do Direito do Trabalho no Brasil. v. 1, t. 1, São Paulo: LTr, 2017. TOLMASQUIM, Mauricio et al. Matriz energética brasileira: uma prospectiva. Novos Estudos, n. 79, p. 47-69, 2007.

TROTSKY, Leon. Balanço e perspectivas. In: TROTKSY, Leon. A teoria da revolução permanente. São Paulo: Sundermann, 2011. TROTSKY, Leon. História da Revolução Russa. Tomo I. Trad. Diego de Siqueira. São Paulo: Sundermann, 2007.

TUC. Trades Union Congress. A short history of british trade unionism: a T.U.C. study pamphlet. London: Trade Union Congress, 1947.

VERÍSSIMO, Gesiele et al. Mortalidade de mineiros brasileiros por câncer entre 1979-2005. Cadernos de Saúde Coletiva, Rio de Janeiro, n. 21, v. 3, p. 281-288, 2013.

VIANNA, Luiz Werneck. Liberalismo e sindicato no Brasil. 3. ed. Rio de Janeiro: Paz e Terra, 1989.

WRIGHT, Ronald. Uma breve história do progresso. Trad. Carolina Araújo. Rio de Janeiro: Record, 2007. 